Euskal ikerketen aldizkaria | Revue d'études basques |

Revista de estudios vascos | Basque studies review

$1 \mid 1996$

Numéro I

\title{
Débuts - Haste
}

\section{Jean-Baptiste Orpustan}

\section{OpenEdition \\ Journals}

Édition électronique

URL : http://journals.openedition.org/lapurdum/1851

DOI : 10.4000/lapurdum.1851

ISSN : 1965-0655

Éditeur

IKER

Édition imprimée

Date de publication : 1 octobre 1996

Pagination : 9-10

ISBN : 2-84127-106-4

ISSN : $1273-3830$

\section{Référence électronique}

Jean-Baptiste Orpustan, « Débuts - Haste », Lapurdum [En ligne], 1 | 1996, mis en ligne le 01 septembre 2010, consulté le 21 septembre 2020. URL : http://journals.openedition.org/lapurdum/1851 ; DOI : https://doi.org/10.4000/lapurdum.1851 


\title{
LAPURDUM
}

I

\author{
Octobre 1996 \\ 1996-ko urrian
}

\author{
Revue annuelle \\ du Centre de recherches sur la langue basque \\ et l'expression en langue basque \\ (ERS 142 du CNRS et de Bordeaux III) \\ et \\ du Département Interuniversitaire d'Études Basques \\ (Faculté pluridisciplinaire de Bayonne)
}

Directeur de la publication: Jean-Baptiste ORPUSTAN

Secrétaire de rédaction: Charles VIDEGAIN

Comité de lecture : Jacques ALLIERES (ERS 142, Toulouse II)

Aurelia ARKOTXA (ERS 142, Bordeaux III)

Pierre BIDART (UPPA)

Francis JAUREGUIBERRY (UPPA)

Jean GOYHENETCHE (docteur en histoire)

Jean HARITSCHELHAR (ERS 142 Bordeaux III)

Maïté LAFOURCADE (UPPA)

Michel MORVAN (ERS 142)

Jean-Baptiste ORPUSTAN (ERS 142, Bordeaux III)

Bernard OYHARÇABAL (ERS 142, CNRS)

Dominique PEILLEN (ERS 142, UPPA)

Georges REBUSCHI (ERS 142, Paris III)

Charles VIDEGAIN (ERS 142, UPPA). 


\section{DÉBUTS}

LAPURDUM : le nom latin, ou du moins latinisé, par lequel les Romains selon leur habitude désignèrent leur camp fortifié, le castrum qui gardait le confluent de la Nive et de l'Adour, servira d'enseigne à la nouvelle revue que le Centre de recherches sur la langue et l'expression en langue basque (ERS 142 du CNRS et de Bordeaux III) et le Département interuniversitaire d'Études basques de l'UFR pluridisciplinaire de Bayonne font paraître pour la première fois en ce mois d'octobre 1996. Le nom, le plus ancien témoignage onomastique sur le lieu où le Moyen Âge verrait naître la ville de Bayonne, n'est pas seulement un signe du passé. Il vit encore aujourd'hui dans le nom basque de la province, LAPURDI, lui-même documenté dès 1110 , et dans ses variantes romanes : le gascon Labort et le moderne et français Labourd.

S'inscrivant par son nom dans une longue tradition d'histoire basque et régionale, la revue $L A P U R D U M$ représentera l'actualité de la recherche scientifique et universitaire dans le domaine de la langue, de la littérature et de la culture basques. C'est que Bayonne est devenue ville universitaire, et même la seule en France qui réunit les formations universitaires des trois cycles en études basques, et où se tient le Centre de recherches ERS 142 du CNRS et de Bordeaux III. Le commencement n'est peut-être pas tout à fait la moitié dans la plupart des choses, comme l'écrivait Oyhénart dans le sonnet en hommage à son prédécesseur Bertrand de Sauguis. Mais une équipe est là, bien établie, qui saura, faisant appel aussi aux concours et échanges extérieurs, donner, année après année, l'image vivante et variée de ses travaux.

\section{HASTE}

Errobi eta Aturriren batzea zaintzen zuen gazteluari Erromatarrek eman zaukoten izen latina, edo bederen latindua, bere ohiduren arabera, LAPURDUM, baliatuko du izenburutzat CNRS eta Bordele III-ko ERS 142 euskararen eta euskaraz egin direnen ikerketako batzordeak eta Baionako Unibertsitate-arteko Euskal Ikastokiak argirat emaiten duten agerkari berriak, lehen aldiko, 1996-ko urri huntan. Izena, Erdi-Aroan Baiona sortzen ikusiko zuen lekuaren izen lekukotasunez zaharrena, ezta bakarrik iraganaren hatz bat. Gaur egun bizi da oraino LAPURDI herrialdearen izenean, ja 1110-ean idatzia, eta haren ondoko erdalki Labort gaskoin eta Labourd oraiko frantzesean. 
Izenaz Euskal-Herri eta ingurunearen ixtorioko jarraikitze luze bati lotuz, LAPURDUM agerkariak ikustera emanen du, euskara, euskal literatura eta kulturan, jakitatearen eta unibertsitateko ikerketaren oraia. Alabainan, Baiona unibertsitateko hiri bilakatu da, gehiago, Frantzian euskal ikasketetako hiru mail unibertsitatekoak biltzen dituen bakarra, eta CNRS-ko eta Bordele III-ko ikerketa batzordea Fakultatean jarria daukana. Hatsarrea ezta behar bada osoki erdia gauza gehienetan, Oihenartek bere aitzineko Beltran Zalgizekoaren ohoreko hamalaurkunean zion bezala. Baina hor da ikertaldea, zutik, jakinen baitu, atzerrikoer hel eginez behar denean eta kampokoekin harremanetan, urtez urte, bere lan mota guzien itxura bizi baten emaiten.

\section{Jean-Baptiste ORPUSTAN}

Professeur à l'Université Michel de Montaigne - Bordeaux III Directeur de l'ERS 142 du CNRS 